\title{
Hubungan Kadar Troponin T dengan Lama Perawatan Pasien Infark Miokard Akut di RSUP Dr. M. Djamil Padang Periode 01 Januari - 31 Desember 2013
}

\author{
Yulia Eka Hastuti ${ }^{1}$, Eka Fithra Elfi ${ }^{2}$, Dian Pertiwi ${ }^{3}$
}

\begin{abstract}
Abstrak
Kadar troponin T memberikan informasi penting dalam estimasi luas infark. Pada IMA, luas infark berhubungan erat dengan nilai prognosis. Luas infark yang melebihi $40 \%$ miokardium juga berkaitan dengan tingginya insiden syok kardiogenik. Keadaan ini yang diduga mendasari perburukan klinis pasien IMA sehingga dapat mempengaruhi lama perawatan. Tujuan penelitian ini adalah menganalisis hubungan kadar troponin $\mathrm{T}$ dengan lama perawatan pasien Infark Miokard Akut (IMA) di RSUP Dr. M. Djamil Padang dengan menggunakan desain penelitian Cross Sectional Study. Penelitian ini menggunakan data sekunder yang diambil di Instalasi Rekam Medik (Medical Record), yaitu data rekam medik pasien yang didiagnosis sebagai IMA yang dirawat inap di RSUP Dr. M. Djamil Padang periode 01 Januari - 31 Desember 2013. Data dianalisis dengan uji korelasi Spearman. Hasil penelitian ini menemukan sebagian besar pasien IMA masuk rumah sakit dengan kadar kadar Troponin T sebesar 0,1-2 ng/ml (68,0\%) dan lama hari rawat sebesar $\geq 5$ hari $(74,0 \%)$. Berdasarkan hasil analisis bivariat yang telah dilakukan, dapat disimpulkan bahwa tidak terdapat hubungan signifikan antara kadar troponin $T$ dengan lama perawatan pasien IMA dengan nilai $p>0,05$ dan nilai koefisien korelasi Spearman $(r)=0,160$ yang menunjukkan korelasi positif dengan derajat hubungan yang lemah/tidak ada hubungan.
\end{abstract}

Kata kunci: infark miokard akut, troponin $\mathrm{T}$, lama perawatan

\begin{abstract}
Troponin T level gives an important information in estimating infarct size. On Acute Myocardial Infarction (AMI), infarct size was closely related to prognosis assessment. Infark size which extends more than $40 \%$ of myocardials are also related to the high incidence of cardiogenic shock. These condition are presumed to be responsible to the clinical worsening of AMI patient and affect the duration of hospitalization. The objective of this study was to analyze the relation between troponin $T$ with duration of hospitalization of AMI patients at Dr. M. Djamil Padang Hospital which using cross sectional study design. This study used secondary data which was taken in Medical Record Installation. Those data consist of AMI patients medical record who were hospitalized in Dr. M. Djamil Padang Hospital on January $1^{\text {st }}$ - December $31^{\text {st }}$ 2013. Data were analized by using Spearman's correlation. This study showing that most of AMI patients were admitted to Hospital with troponin T level 0,1-0,2 $\mathrm{ng} / \mathrm{ml}(68 \%)$ and the duration of hospitalization was $\geq 5$ days (74\%). Result of bivariate analysis using Spearman's correlation was not having significant relation between troponin $T$ with duration of hospitalization of AMI patients $p>0,05$ and Spearman's correlation $(r)=0.160$ which showing positive correlation with low correlation degree or no correlation.
\end{abstract}

Keywords: acute myocardial infarction, troponin $T$, duration of hospitalization

Affiliasi penulis: 1. Prodi Profesi Dokter 2011 FK Unand (Fakultas Kedokteran Universitas Andalas Padang), 2. Bagian Kardiologi dan Kedokteran Vaskuler FK Unand, 3. Bagian Patologi Klinik FK Unand.
Korespondensi: Yulia Eka Hastuti, Email: yulia.eh15@gmail.com Telp/Hp: 081278891734. 


\section{PENDAHULUAN}

Infark Miokard Akut (IMA) adalah kerusakan jaringan miokard akibat iskemia hebat yang terjadi secara tiba - tiba. ${ }^{1}$ Keadaan ini biasanya disebabkan oleh ruptur plak yang diikuti dengan proses pembentukan trombus oleh trombosit. ${ }^{2}$

Berdasarkan laporan World Health Organization (WHO) pada tahun 2008, infark miokard merupakan penyebab kematian utama di dunia. Terhitung sebanyak 7,25 juta $(12,8 \%)$ kematian terjadi akibat penyakit ini di seluruh dunia. ${ }^{3}$ Menurut data statistik National Health and Nutrition Examination Survey (NHANES) 2007 - 2010, prevalensi infark miokard lebih banyak diderita laki - laki dibandingkan perempuan. ${ }^{4}$ Kejadian ini mulai meningkat pada laki laki saat berusia $\geq 45$ tahun dan perempuan $\geq 55$ tahun. ${ }^{5}$

Penyakit IMA juga merupakan salah satu masalah kesehatan di Indonesia. Laporan Riskesdas tahun 2007 memperlihatkan bahwa penyakit infark miokard termasuk 10 penyebab kematian terbanyak dengan proporsi kematian sebesar 5,1\%. ${ }^{6}$ Menurut data Sistem Informasi Rumah Sakit (SIRS) tahun 2010, penyakit infark miokard menduduki peringkat 10 besar Penyakit Tidak Menular (PTM) yang menyebabkan rawat jalan $(1.88 \%)$ dan rawat inap $(2,29 \%)$ rumah sakit di Indonesia. ${ }^{7}$

Berdasarkan data awal yang diperoleh dari Rekam Medik RSUP Dr. M. Djamil Padang periode 01 Januari - 31 Desember 2012 diketahui bahwa jumlah pasien IMA rawat inap di RSUP Dr. M. Djamil Padang mencapai 321 orang. Berdasarkan data tersebut, diperkirakan 207 orang (64,5\%) menunjukkan kasus STEMI, sedangkan sisanya tercatat menderita NSTEMI.

Kriteria diagnosis IMA menurut The Third Universal Definition of $\mathrm{MI}$ diperoleh dari bukti kenaikan kadar troponin ditambah dengan minimal satu dari lima kriteria diagnostik. ${ }^{8}$ Troponin dipilih menjadi biomarker pilihan untuk mendiagnosis IMA karena memiliki sensitifitas dan spesifisitas yang lebih unggul dibandingkan biomarker sebelumnya, yaitu Creatine Kinase Isoenzyme $M B{ }^{9}$

Penelitian tentang sensitivitas dan spesifisitas troponin T dan I untuk mendiagnosis IMA telah banyak dilakukan. Data penelitian menunjukkan bahwa troponin I memiliki sensitifitas dan spesifisitas sedikit lebih tinggi dibandingkan dengan troponin T. Meskipun demikian, troponin $\mathrm{T}$ dianggap lebih tepat digunakan sebagai kriteria diagnosis IMA karena memiliki nilai cut off yang relatif seragam, sehingga variasi sensitivitas dan spesifisitas antar produk relatif lebih kecil. ${ }^{10}$ Penelitian oleh Yaswir pada tahun 2002 di RSKJ Sumatra Barat melaporkan bahwa troponin $\mathrm{T}$ mempunyai sensitifitas $91,9 \%$ dan spesifisitas $100 \%$ dalam deteksi kerusakan sel miokard. ${ }^{11}$

Beberapa penelitian menunjukkan bahwa kadar troponin $\mathrm{T}$ juga memberikan informasi penting dalam menentukan luas infark. ${ }^{12}$ Pernyataan ini didukung oleh penelitian Arruda-Olson et al yang membuktikan bahwa kadar troponin $T$ pada hari 1,2 dan 3 berkorelasi positif dengan luas infark miokard. ${ }^{13}$

Pada IMA, luas infark berhubungan erat dengan nilai prognosis. Luas infark merupakan faktor penentu fungsi ventrikel kiri pasca infark, berupa penurunan Left Ventrikel Ejection Fraction (LVEF). Penurunan LVEF ini selanjutnya akan berpengaruh terhadap penurunan cardiac output yang kemudian dapat menimbulkan efek kompensasi jangka panjang yang merugikan. ${ }^{14}$ Keadaan ini yang diduga mendasari perburukan klinis pasien IMA sehingga dapat mempengaruhi lama perawatan.

Hasil studi ada yang melaporkan bahwa ada hubungan antara kadar troponin $\mathrm{T}$ dengan angka mortalitas dan morbiditas yangsemakin tinggipada pasien IMA. Penelitian kohort oleh Gerber et al pada tahun 2012 di Olmsted County Minnesota mengelompokkan 1177 pasien menjadi 3 kategori berdasarkan kadar troponin $\mathrm{T}$, yaitu kadar troponin rendah ( $\leq 0.22)$, kadar troponin sedang (0.23-1.17) dan kadar troponin tinggi $(\geq 1.18)$. Hasil studi membuktikan bahwa peningkatan kadar troponin $\mathrm{T}$ berkaitan secara bermakna dengan tingginya risiko kematian, iskemia berulang, dan gagal jantung dalam 30 hari. ${ }^{15}$ Penelitian serupa juga pernah dilakukan oleh Tarigan pada tahun 2003 di beberapa RS di Medan, dari 35 pasien Sindrom Koroner Akut (SKA) dijumpai 30 (85,7\%) kadar troponin $\mathrm{T}>0,1 \mathrm{ng} / \mathrm{ml}$, dan dari troponin $\mathrm{T}>0,1$ $\mathrm{ng} / \mathrm{ml}$ didapatkan 23 (76,7\%) mengalami komplikasi. Komplikasi terbanyak adalah syok yaitu pada $76 \%$ 
pasien, disusul dengan kematian pada $17,1 \%$ pasien dimana kadar troponin $\mathrm{T}$ pasien yang meninggal $>2$ $\mathrm{ng} / \mathrm{ml}$, sedangkan pasien dengan Troponin $\mathrm{T}<0,1$ $\mathrm{ng} / \mathrm{ml}$ tidak ada mengalami komplikasi yang fatal. ${ }^{16}$

Berdasarkan latar belakang di atas, perlu dilakukan sebuah penelitian mengenai hubungan kadar troponin $\mathrm{T}$ dengan lama perawatan pada pasien Infark Miokard Akut di RSUP Dr. M. Djamil Padang.

\section{METODE}

Jenis penelitian ini adalah analitik observasional dengan menggunakan desain cross sectional study. Penelitian dilakukan dilnstalasi Rekam Medik (Medical Record) RSUP Dr. M. Djamil Padang. Pelaksanaan penelitian dilakukan selama lima bulan (Mei - September 2014). Sampel dalam penelitian ini sebanyak 50 orang. Sampel merupakan pasien dengan diagnosis utama Infark Miokard Akut (IMA) yang dirawat inap di RSUP Dr. M. Djamil Padang periode 01 Januari -31 Desember 2013 yang memenuhi kriteria inklusi dan tidak memiliki kriteria eksklusi. Sampel ditentukan dengan menggunakan teknik total sampling. Data yang diperoleh diolah dengan uji korelasi Spearman dengan tingkat kemaknaan $p>0,05$.

\section{HASIL DAN PEMBAHASAN}

\section{Gambaran Umum}

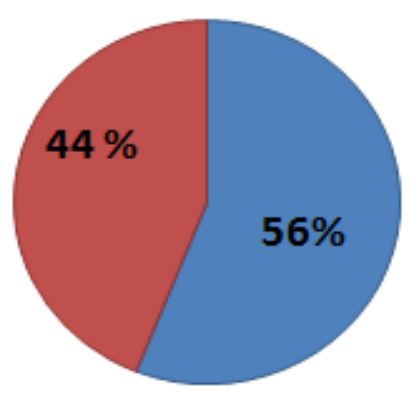

$\square$ STEMI $\square$ NSTEMI

Gambar 1. Distribusi frekuensi sampel penelitian berdasarkan diagnosis utama

Berdasarkan Gambar 1 di atas dapat dilihat bahwa sebagian besar pasien IMA yang yang menjadi sampel penelitian didiagnosis dengan kasus STElevation Myocardial Infarction) STEMI, yaitu sebanyak 28 orang $(56,0 \%)$. Hasil ini hampir serupa dengan penelitian yang dilakukan Zahara (2013) di RSKJ Sumatera Barat, dimana diagnosis utama terbanyak pada pasien SKA adalah kasus STEMI, yaitu 51 orang $(52,0 \%){ }^{17}$

\section{Karakteristik Sampel}

Tabel 1. Karakteristik sampel

\begin{tabular}{lcc}
\hline Karakteristik Sampel & Frekuensi & Persentase (\%) \\
\hline Jenis Kelamin & 43 & 86,0 \\
Laki - laki & 7 & 14,0 \\
Perempuan & $\mathbf{5 0}$ & $\mathbf{1 0 0 , 0}$ \\
\hline \multicolumn{1}{c}{ Total } & & \\
\hline Umur & 53,80 & \\
Mean & 9,313 & \\
SD & 54,50 & \\
Median & 70 & \\
Maximum & 22 & \\
Minimum & 3 & 6,0 \\
$<40$ tahun & 12 & 24,0 \\
40-49 tahun & 21 & 42,0 \\
50-59 tahun & 14 & 28,0 \\
$\geq 60$ tahun & $\mathbf{5 0}$ & $\mathbf{1 0 0 , 0}$ \\
\hline \multicolumn{1}{c}{ Total } &
\end{tabular}

Tabel 1 dapat dilihat bahwa sebagian besar pasien IMA yang menjadi sampel dalam penelitian ini berjenis kelamin laki- laki, yaitu sebanyak 43 orang $(86,0 \%)$ dan sisanya berjenis kelamin perempuan $(14,0 \%)$.Hal tersebut serupa dengan penelitian yang dilakukan oleh Siregar di RSUP Adam Malik Medan yang melaporkan bahwa pasien laki-laki dengan IMA lebih banyak dibandingkan dengan perempuan, yaitu $88,4 \%{ }^{18}$

Pada penelitian ini didapatkan umur pasien IMA yang bervariasi dengan umur terendah adalah 22 tahun dan tertinggi adalah 70 tahun. Rerata umur pasien IMA pada penelitian ini adalah $53,80 \pm 9,313$ tahun. Hal ini tidak terlalu berbeda dengan penelitian oleh Irawan et al pada tahun 2005 di Intensive Cardiac Care Unit (ICCU) RS Dr. Sardjito yang menyebutkan bahwa usia rerata pasien IMA adalah 55 tahun. ${ }^{19}$ 


\section{Kadar troponin T}

Tabel 2. Distribusi frekuensi sampel penelitian berdasarkan kadartroponin $\mathrm{T}$

\begin{tabular}{ccc}
\hline Kadar Troponin $(\mathbf{n g} / \mathrm{ml})$ & Frekuensi & (\%) \\
\hline $\begin{array}{c}\text { Low Risk/Negatif } \\
(<0,03 \mathrm{ng} / \mathrm{ml})\end{array}$ & 0 & 00,0 \\
$\begin{array}{c}\text { Medium Risk } \\
(0,03-0,1 \mathrm{ng} / \mathrm{ml}) \\
\text { High Risk } \\
(0,1-2 \mathrm{ng} / \mathrm{ml})\end{array}$ & 16 & 32,0 \\
\hline Total & 34 & 68,0 \\
\hline
\end{tabular}

Pada Tabel 2 dapat dilihat bahwa sebagian besar pasien IMA yang menjadi sampel dalam penelitian ini memiliki kadar Troponin $\mathrm{T}$ sebesar 0,1-2 $\mathrm{ng} / \mathrm{ml}(68,0 \%)$. Sebuah penelitian yang dilakukan di RS Dr. Wahidin Sudirohusodo Makassar (Maret - Juli 2005) juga memiliki hasil yang tidak jauh berbeda dengan penelitian oleh peneliti yang melaporkan bahwa dari 42 pasien yang terdiagnosis sebagai IMA $63,4 \%$ masuk dengan kadar troponin $\mathrm{T} 0,1-2 \mathrm{ng} / \mathrm{ml}$, $21,9 \%$ masuk dengan kadar troponin $\mathrm{T}>2 \mathrm{ng} / \mathrm{ml}$, dan sisanya $14,6 \%$ masuk dengan kadar troponin negatif. ${ }^{20}$

\section{Lama Perawatan}

Tabel 3. Distribusi frekuensi sampel penelitian berdasarkan lama perawatan

\begin{tabular}{ccc}
\hline Lama Perawatan & Frekuensi & $\mathbf{( \% )}$ \\
\hline$<5$ hari & 13 & 26,0 \\
$\geq 5$ hari & 37 & 74,0 \\
\hline Total & $\mathbf{5 0}$ & $\mathbf{1 0 0 , 0}$ \\
\hline
\end{tabular}

Tabel 3 memperlihatkan bahwa pasien IMA yang menjadi sampel dalam penelitian ini terbanyak dirawat inap selama $\geq 5$ hari yaitu sebanyak 37 orang $(74,0 \%)$ dan selebihnya hanya dirawat $<5$ hari $(26,0 \%)$. Pada penelitian ini didapatkan lama perawatan pasien IMA terendah adalah 1 hari dan tertinggi adalah 12 hari. Rerata lama perawatan pasien IMA yang dirawat inap di RS pada penelitian ini adalah 5,24 $\pm 2,016$ hari. Hasil penelitian ini tidak jauh berbeda dengan data awal dari RSUP Dr. M. Djamil Padang periode 1 Januari 2013 - 31 Desember 2013 yang dikumpulkan sebelum penelitian ini dilakukan yang menyebutkan bahwa lama hari rawat inap pasien IMA berkisar $5-6$ hari.

\section{Analisis Bivariat}

Tabel 4. Hasil analisis kadar troponin $\mathrm{T}$ dengan lama perawatan pasien IMA

\begin{tabular}{cccc}
\hline & Rerata & $\mathbf{r}$ & $\mathbf{p}$ \\
\hline Kadar Troponin T & $0,5126 \pm 0,54425$ & $+0,160$ & 0,266 \\
$\begin{array}{c}\text { Lama perawatan } \\
\text { pasien IMA }\end{array}$ & $5,24 \pm 2,016$ & & \\
\hline
\end{tabular}

Tabel 4 memperlihatkan bahwa penelitian ini mendapatkan nilai koefisien korelasi Spearman ( $r$ ) sebesar +0,160, yang menunjukkan korelasi positifdengan derajat hubungan yang lemah / tidak ada hubungan dan tarif signifikansi $(p)$ sebesar 0,266 $(p>0,05)$ yang menunjukkan bahwa tidak terdapat korelasi bermakna diantara kedua variabel. Hal ini berarti tidak terdapat hubungan yang bermakna antara kadar troponin Tdengan lama perawatan pasien IMA.

Hasil ini tidak sejalan dengan penelitian sebelumnya yang melaporkan bahwa ada hubungan antara kadar troponin $\mathrm{T}$ dengan angka mortalitas dan morbiditas yang semakin tinggi pada pasien IMA. Penelitian kohort oleh Gerber et al pada tahun 2012 membuktikan bahwa peningkatan kadar troponin $\mathrm{T}$ berkolerasi positif dengan peningkatan risiko kematian, iskemia berulang, dan gagal jantung dalam 30 hari pasca infark. Penelitian yang diikuti oleh 1177 pasien ini dikelompokkan menjadi 3 kategori berdasarkan kadar troponin $\mathrm{T}$, yaitu kadar troponin rendah ( $\leq 0.22)$, kadar troponin sedang (0.23-1.17) dan kadar troponin tinggi $(\geq 1.18)$. Hasil studi melaporkan bahwa risiko morbiditas dan mortalitas dalam 30 hari berhubungan dengan kadar troponin $\mathrm{T}$. Risiko kematian pada pasien dengan kadar troponin rendah $6,9 \%$, sedang $5,8 \%$, dan tinggi $12,7 \%$. Risiko iskemik berulang pada pasien dengan kadar troponin rendah $10,2 \%$, sedang $12,7 \%$, dan tinggi $15,4 \%$. Risiko gagal jantung pada pasien dengan kadar troponin rendah $17,9 \%$, sedang $19,0 \%$, dan tinggi $24,8 \%{ }^{15}$

Penelitian ini sejalan dengan penelitian yang dilakukan oleh Arruda-Olson et al pada tahun 2011 yang menyimpulkan bahwa kadar troponin $\mathrm{T}<12$ jam tidak berhubungan dengan luas infark miokard. Korelasi antara troponin $\mathrm{T}$ dan luas infark hanya terjadi di hari 1,2 , dan $3 .{ }^{13}$ Pada penelitian ini sebagian besar troponin $\mathrm{T}$ yang diperoleh adalah troponin $\mathrm{T}<12 \mathrm{jam}$. 


\section{SIMPULAN}

Tidak terdapat hubungan antara kadar troponin T dengan lama perawatan pasien IMA di RSUP Dr. M. Djamil Padang.

\section{DAFTAR PUSTAKA}

1. Karim S, Kabo P. EKG dan penanggulangan beberapa penyakit jantung untuk dokter umum. Jakarta: FKUI; 2007.hlm.141-48.

2. Irmalita. Infark miokard. Dalam: Rilantono LI, Baraas F, Karo SK, Roebiono PS, editor (penyunting). Buku ajar kardiologi . Jakarta: FKUI; 2002.hlm.173-80.

3. World Health Organization (WHO). The top ten causes of death 2008. 2011 (diunduh 15 Februari 2014). Tersedia dari: URL: HYPERLINK http://www.who.int/mediacentre/factsheets/fs310 2 008.pdf

4. Go AS, Mozaffarian D, Roger VL, Benjamin EJ, Berry JD, Borden WB, et al. Heart disease and stroke statistics 2013 update: a report from the American Heart Association. Circulation. 2013;127: 6-245.

5. Brown CT. Penyakit aterosklerotik koroner. Dalam: Price SA, Wilson LM, editor (penyunting). Patofisiologi konsep klinis proses-proses penyakit. Edisi ke-6. Jakarta: EGC; 2012.hlm.576-612.

6. Departemen Kesehatan Republik Indonesia. Profil kesehatan Indonesia 2008. 2009 (diunduh 15 Februari 2014). Tersedia dari: URL: HYPERLINK http://www.depkes.go.id/downloads/publikasi/Profil \%20Kesehatan\%20Indonesia\%202008.pdf

7. Kementrian Kesehatan Republik Indonesia. Penyakit tidak menular. 2012 (diunduh 15 Februari 2014). Tersedia dari: URL: HYPERLINK http://www.depkes.go.id/downloads/BULETIN\%20 PTM.pdf

8. Thygesen K, Alpert JS, Jaffe AS, Simoons ML, Chaitman BR, White HD. Third universal definition of myocardial infarction. JACC. 2012;60(10):1-18.

9. Samsu N, Sargowo D. Sensitivitas dan spesifisitas troponin $\mathrm{T}$ dan I pada diagnosis infark miokard akut. Majalah Kedokteran Indonesia. 2007;57(10): 363-72.
10. Nagesh CM, Roy A. Role of biomarkers in risk stratification of acute coronary syndrome. Indian J Med Res. 2010;132:627-33.

11. Yaswir R. Pemeriksaan troponin T pada penderita infark miokard akut di rumah sakit khusus jantung sumatera barat periode januari 1998 - desember 1999. Majalah Kedokteran Andalas. 2002;26(1):15.

12. Katus HA, Giannitsis E. Biomarkers of necrosis for risk assessment and management of ST-elevation myocardial infarction. Dalam: Cardiovascular biomarkers: pathophysiology and disease management. Morrow DA, editor (penyunting). New Jersey: Humana Press; 2006.hlm.91-100.

13. Arruda-Olson A, Roger VL, Jaffe AS, Hodge DO, Gibbons RJ, Miller TD. Troponin T levels and infarct size by SPECT myocardial perfusion imaging. JACC. 2011;4(5):523-33.

14. Hallén, J. Troponin for the estimation of infarct size:what have we learned?. Cardiology. 2012;121: 204-12.

15. Gerber $Y$, Jaffe AS, Weston SA, Jiang R, Roger $V L$. Prognostic value of cardiac troponin $T$ after myocardial infarction: a contemporary community experience. Mayo Clin Proc . 2012;87(3):247-54.

16. Tarigan $\mathrm{E}$. Hubungan kadar troponin $\mathrm{T}$ dengan gambaran klinis penderita sindroma koroner akut (tesis). Medan: Fakultas Kedokteran Universitas Sumatera Utara; 2003.

17. Zahara F. Gambaran profil lipid pada pasien sindrom koroner akut di Rumah Sakit Khusus Jantung Sumatera Barat tahun 2011 - 2012 (skripsi). Padang: Fakultas Kedokteran Universitas Andalas; 2013.

18. Siregar YF. Hubungan antara luas infark miokard berdasarkan hasil EKG dengan kadar troponin $T$ pada penderita infark miokard akut STEMI dan NSTEMI di RSUP H. Adam Malik Medan dari 01 januari 2008 - 31 desember 2009 (skripsi). Medan: Fakultas Kedokteran Universitas Sumatera Utara; 2009.

19. Irawan B, Suharno, Rochmah W. Hubungan kadar gula darah saat masuk rumah sakit dengan cardiac events pada penderita infark miokard akut di RS Sardjito Yogyakarta. Jurnal Kedokteran Brawijaya. 2005;XXI(1):37-43. 
20. Nawawi RA, Fitriani RB, Hardjoeno. Troponin T value/cTnT of patients with acute coronary syndrome. Indonesian Journal of Clinical Pathology and Medical Laboratory. 2006;12(3):123-26. 